agulation and hemostasis in cardiac surgical patients. J Card Surg 1994;9:443-61.

3. Altés A, Martino R, Gari M, et al. Heparin induced thrombocytopenia and heart operation: management with tedelparin. Ann Thorac Surg 1995;59:508-9.

4. Koza ML, Messmore HL, Wallock ME, Walenga JM, Pifarre
ME. Evaluation of a low molecular weight heparin as an anticoagulant in a model of cardiopulmonary bypass surgery. Thromb Res 1993;70:67-76.

5. Jones DR, Hill RC, Vasilakis A, et al. Safe use of heparincoated bypass circuits incorporating a pump-oxygenator. Ann Thorac Surg 1994;57:815-9.

\title{
REOPERATION FOR ANEURYSMAL DISEASE OF THE ASCENDING AORTA IN PATIENTS WITH CONCOMITANT AORTIC VALVE INCOMPETENCE
}

\author{
Matthias Karck, MD, ${ }^{\mathrm{a}}$ Joachim Cremer, MD, ${ }^{\mathrm{a}}$ ürgen Wawersik, MD, ${ }^{\mathrm{b}}$ and Axel Haverich, MD, ${ }^{\mathrm{a}}$ Kiel, Germany
}

An incompetent aortic valve in the presence of recurrent pathologic processes of the ascending aorta poses challenges during surgical reentry of the mediastinum. This is particularly true of patients who have undergone previous cardiac or aortic operations in which the pericardium was left open with an ascending aortic aneurysm encroaching on the sternum. Our experience with seven consecutive successful reoperations on patients with such combined lesions is described.

The patient cohort consisted of seven consecutive patients operated on between October 1993 and February 1995. In all patients except one, the femoral artery and vein were exposed by groin incision. In two patients the sternum was reopened with an oscillating saw without the previous institution of femoro-femoral bypass. Retrosternal adhesions were then carefully dissected to make feasible the institution of cardiopulmonary bypass by means of ascending aortic and right atrial cannulation. In five patients, cardiopulmonary bypass was commenced through groin cannulation and the systemic temperature was lowered slightly. In two instances, complete median resternotomy was then performed with an oscillating saw. In both of these cases, subsequent dissection of retrosternal adhesions was possible without major bleeding. The aorta was then mobilized to enable aortic crossclamping. After aortotomy, the procedures were completed according to standard techniques.

In a subgroup of three patients, however, only the lower third of the sternal bone was reopened during femorofemoral cardiopulmonary bypass. With the sternal edges kept carefully elevated, the diaphragmatic aspects of the left and right ventricle were dissected first, and all retrosternal adhesions were left untouched. Then both the lateral wall of the left ventricle and the apex were exposed

From the Departments of Cardiovascular Surgery and Department of Anaesthesiology, University of Kiel, Kiel, Germany.

Received for publication Nov. 13, 1995; accepted for publication Feb. 15, 1996.

J Thorac Cardiovasc Surg 1996;112:1392-3

Copyright (c) 1996 by Mosby-Year Book, Inc.

$0022-5223 / 96 \$ 5.00+0 \quad \mathbf{1 2 / 5 4 / 7 2 8 9 5}$ to such an extent that the apex could be punctured for placement of a vent catheter. In the event of ventricular fibrillation, the heart was decompressed manually to avoid ventricular overdistention, which could well occur despite left ventricular venting. Core cooling was continued to achieve a rectal temperature of $25^{\circ} \mathrm{C}$ before induction of circulatory arrest. The systemic blood was drained, leading to partial collapse of both the heart and the ascending aorta.

Resternotomy and dissection of the remaining retrosternal adhesions were completed, safely and without damage to the adjacent right ventricle, pulmonary artery, or ascending aorta. The aorta was then mobilized as far downstream as was possible without compromising the brachiocephalic trunk. At this point, an aortic occluding clamp was gently applied and cardiopulmonary bypass was reinstituted. The time required to complete dissection of retrosternal adhesions during circulatory arrest was less than 12 minutes in all cases. In this subgroup of three patients, the body of the aneurysm was then incised anteriorly and longitudinally. In one patient, ascending aortic pathologic processes, including a chronic type A dissection with rupture of the false channel into the pleural space and additional paravalvular leakage of the previously implanted mechanical aortic valve, were seen. The other two patients had typical intimal tears in the ascending aorta as a result of acute type $\mathrm{A}$ aortic dissection, with a significant paravalvular leakage of the aortic valve prosthesis in one case. The aortic valve prosthesis in the other patient appeared competent, but it had to be replaced because massive enlargement of the sinus of Valsalva precluded secure anchoring of an ascending aortic graft except as a composite graft. In all three patients of this subgroup, composite graft replacement of the aortic valve and ascending aorta was initially performed. Meanwhile, the systemic temperature was further lowered to $20^{\circ} \mathrm{C}$. At this rectal temperature, a second period of circulatory arrest was induced to enable exploration of the aortic arch and subsequent distal reconstruction if necessary. After implantation of the distal aortic anastomosis, cardiopulmonary bypass was reinstituted. During rewarming, the graft-to-graft anastomosis was 


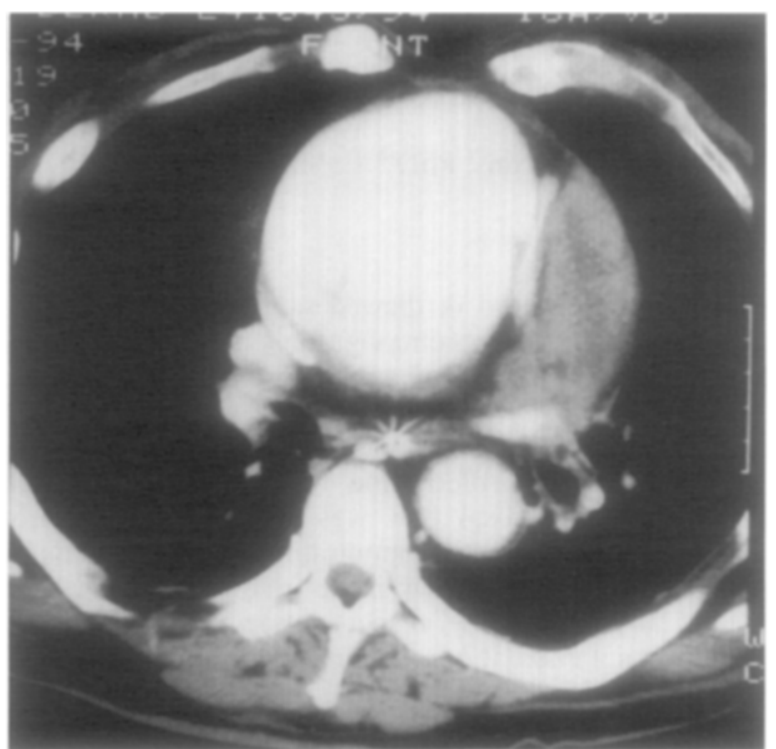

Fig. 1. Preoperative computed tomographic scan of chest. This patient, who had undergone mechanical aortic valve replacement and repair of funnel chest with resection of sternal bone 15 years previously, had acute type A aortic dissection and ascending aortic aneurysm.

completed before reperfusion of the heart was commenced.

All patients were successfully weaned from cardiopulmonary bypass. Of the entire cohort of seven patients, one patient died 2 months after operation of preexisting chronic respiratory and renal failure. The postoperative courses of the other patients were uneventful, and they are alive at follow-up periods of 16 to 23 months after operation.

The prevalence of reoperation on the ascending aorta ranges from $6 \%$ to $22 \%{ }^{1-3}$ These interventions bear an increased surgical risk because exposure and control of circulation are more complicated and unusual anatomic presentations may necessitate an individualized approach rather than standard technique. This is particularly true in cases where an ascending aortic tube graft or an aneurysm closely adherent to the chest wall is combined with severe aortic valve incompetence (Fig. 1). The approach to these combined lesions requires deviation from the routine longitudinal sternotomy to avoid both fatal bleeding and left ventricular overdistention. In such instances a fifth rib bilateral or unilateral thoracotomy and transverse sternotomy before the institution of right atrial-femoral or femoro-femoral bypass were recommended by Kirklin and Barratt-Boyes ${ }^{4}$ before resternotomy.
A variation of this approach evolved in our recent cases of ascending aortic reoperations in the presence of aortic valvular incompetence. Instead of completing the resternotomy at moderate hypothermia, we prefer to perform first a limited, inferior resternotomy. Dissection of the diaphragmatic aspects of both the left and right ventricle enables the introduction of an apical vent. With the vent in place, core cooling is continued until the onset of ventricular fibrillation. If inadequate perfusion pressure prevents sufficient lowering of the temperature and clamping of the aorta is impossible because of scar tissue or difficult exposure, occlusion of the aorta by apical insertion and inflation of a balloon catheter in the ascending aorta is an option. ${ }^{5}$ Additionally, with the heart now accessible to manual decompression, we are able to prevent overdistention of the left ventricle, which may well occur despite venting. At a rectal temperature of $25^{\circ} \mathrm{C}$, circulatory arrest is induced and the blood is drained into the cardiotomy reservoir. Under these conditions, the heart and the ascending aorta tend to collapse, which makes dissection of retrosternal adhesions and completion of resternotomy much easier and safer. Cardiopulmonary bypass is reinstituted once the ascending aorta is dissected free and clamped. Then either the core temperature can be further lowered to $20^{\circ} \mathrm{C}$ before reinduction of circulatory arrest whenever the correction of an aortic arch pathologic process is necessary or moderate hypothermia $\left(25^{\circ} \mathrm{C}\right)$ can be maintained during the repair of the ascending aorta.

In view of our favorable experience, we suggest this strategy for all cases in which preoperative computed tomography shows close adherence of the ascending aorta or the right ventricle to the sternum, especially in combination with severe aortic valve incompetence.

\section{REFERENCES}

1. Moreno-Cabral CE, Miller DC, Mitchell RS, Stinson EB, Oyer PE, Jamieson SW, et al. Degenerative and atherosclerotic aneurysm of the thoracic aorta: determinants of early and late surgical outcome. J Thorac Cardiovasc Surg 1984;88:102032.

2. Carrel T, Pasic M, Jenni R, Tkebuchava T, Turina M. Reoperations after operation on the thoracic aorta: etiology, surgical techniques, and prevention. Ann Thorac Surg 1993;56:25969.

3. Bachet JE, Tenignon J, Dreyfus G, Goudot B, Martinelli L, Piquois A, et al. Aortic dissection: prevalence, cause, and results of late reoperations. J Thorac Cardiovasc Surg 1994; 108:199-206.

4. Kirklin JW, Barratt-Boyes BG. Cardiac surgery. 2nd ed. New York: Churchill Livingstone, 1993;523.

5. Crawford ES, Crawford JL, Safi HJ, Coselli JS. Redo operations for recurrent aneurysmal disease of the ascending aorta and transverse aortic arch. Ann Thorac Surg 1985;40:439-55. 